Gynäkologe 2019·52:773

https://doi.org/10.1007/s00129-019-4491-x

Online publiziert: 9 . August 2019

(c) Springer Medizin Verlag GmbH, ein Teil von Springer Nature 2019

\section{Erwiderung}

Zum Leserbrief von Günterberg K (2019) Trichomoniasis - eine Krankheit, die viele Fragen aufwirft. Die Übertragung ausschließlich sexuell? Gynäkologe 52(10). https://doi.org/10. 1007/s00129-019-4489-4

Originalbeitrag: Hof H (2018) Trichomoniasis - wer kennt sie überhaupt noch? Gynäkologe 51:1071-1078. https://doi.org/10.1007/ s00129-018-4357-7

Wie oft ist auch bei der Trichomoniasis die klinische Beobachtung und Erfahrung der Schlüssel zur erfolgreichen Diagnostik und Therapie.

Die diversen Erreger von STD (sexuell übertragbaren Erkrankungen) unterscheiden sich in der Pathogenese. Während Chlamydien und Gonokokken sich ganz bzw. überwiegend intrazellulär vermehren, dringt Trichomonas nicht in die Wirtszelle ein, sondern adhäriert und triggert mittels Pathogenitätsfaktoren eine entzündliche Reaktion.

Ein Lebenszyklus außerhalb des Menschen, wie bei manchen anderen Infektionserregern, ist für Trichomonas bislang nicht bekannt.

Deswegen ist es spekulativ, andere Übertragungswege als eben direkt von Mensch zu Mensch zu postulieren. Ein vollzogener Geschlechtsverkehr ist in der Tat bei der Übertragung von diversen Erregern von STD nicht absolute Voraussetzung; der enge körperliche Kontakt reicht oft aus. Während Chlamydien und Gonokokken außerhalb des Menschen eine begrenzte Überlebenschance haben, sodass auch Schmierinfektionen eine gewisse Rolle spielen, sind Trichomonaden extrem anfällig.

Die Unterschiede bezüglich intra-/ extrazellulärer Vermehrung und der relativen Umweltstabilität sind vermut-

Herbert Hof

MVZ Labor Limbach und Kollegen, Heidelberg, Deutschland

\title{
Die Trichomoniasis ist in der Tat gar nicht so selten!
}

lich - neben dem Sexualverhalten verantwortlich für die unterschiedliche Prävalenz bei verschiedenen Altersstufen der Frauen (Abb. 3 der Publikation).

Dass die Angaben über die Inkubationszeiten so variabel sind (4-23 Tage), zeigt in der Tat eine Unsicherheit.

Die Klinik ist oft hinweisend für eine Trichomoniasis. Aber es gibt, wie im Leserbrief ausgeführt, andere Krankheitsentitäten mit ähnlicher Symptomatik. Zumindest in einigen Fällen ist also eine weitere Abklärung notwendig. Die mikroskopische Untersuchung von Nativmaterial direkt am Untersuchungsstuhl ist ein entscheidender Schritt in der Diagnostik. (Eine Färbung nach vorheriger Fixierung des Untersuchungsmaterials ist für den Nachweis von Trichomonas vaginalis ungeeignet!). Die Kultur, die von der GKV (Gesetzlichen Krankenversicherung) dem Labor honoriert wird, ist offensichtlich in der Praxis wenig tauglich. Deswegen kommt den molekularbiologischen Nachweisverfahren, die international üblich sind, auch bei uns ein hoher Stellenwert zu; da die DNA grundsätzlich umweltstabil ist, gelingt ein positiver Nachweis auch nach längerem Transport.

Wegen der doppelt so langen Halbwertszeit von Tinidazol wäre also dieses Medikament im Prinzip dem Metronidazol für die Therapie vorzuziehen. In der Tat ist mit einem gelegentlichen Therapieversagen nach einer einmaligen oralen Gabe (was natürlich praktisch am ehesten realisierbar ist) von Metronidazol zu rechnen. Deswegen ist - wie ausgeführt - eine mehrfache Gabe sicherer.

\section{Korrespondenzadresse}

Prof. Dr. med. Herbert Hof

MVZ Labor Limbach und Kollegen

Im Breitspiel 16, 69126 Heidelberg,

Deutschland

herbert.hof@labor-limbach.de

Interessenkonflikt. H. Hof gibt an, dass kein Interessenkonflikt besteht. 